\title{
An Integrated Smarter Cutting Parameter Selection System with a Case Study for Pocket Milling
}

\author{
Yung-Chou Kao1,2,*, Da-Min Lin'1, Jian-Zhang Wu1, and Trung-Kien \\ Vi ${ }^{1}$ \\ ${ }^{1}$ Department of Mechanical Engineering, National Chung Cheng University, Chiayi, Taiwan, R.O.C. \\ ${ }^{2}$ Advanced Institute of Manufacturing with High-tech Innovations, National Chung Cheng University, Chiayi, Taiwan, R.O.C. \\ (Received 7 December 2017; Accepted 11 January 2018; Published on line 1 June 2018) \\ *Corresponding author: imeyckao@ccu.edu.tw \\ DOI: 10.5875 /ausmt.v8i2.1681
}

\begin{abstract}
This paper develops an integrated smart cutting parameter selection system for pocket milling. Currently, general CAD/CAM systems generate pocket milling tool paths according to user-designated cutting parameters typically including cutting depth, feed rate, and spindle speed. Pocket milling is often used for rough machining, and shorter cutting times are used to increase productivity. Although shorter machining times can be accomplished with deeper cutting, it may result in unstable cutting (chatter). Stability lobe diagrams (SLD) generated from cutting and tapping tests on selected machine tools describe the relationship between cut depth and spindle speed. However, despite offering useful information for selecting cutting parameters for chatter-free cutting, SLD has not been integrated with existed CAD/CAM systems. Therefore, this study integrates SLD in a CAD/CAM system to effectively determine the optimum cut depth and spindle speed for a theoretically chatter free pocket milling tool path. A case study is used to verify the proposed system integration.
\end{abstract}

Keywords: Pocket Milling; Stability Lobe Diagram; Cutting Parameters Selection

\section{Introduction}

Most metal machining companies operate at the small-to-medium sized enterprise (SME) scale, which allows them to pursue unique and innovative technologies but can leave them subject to resource limitations. They also struggle with insufficient production staff, relatively low technical capability, and frequently are contracted to produce work pieces in small quantities and large variation, thus incurring increased R\&D and prototyping costs. The establishment of a common database of innovative and unique digital technologies could help such firms collect and access domain expertise and knowhow, improve talent cultivation, and enhance enterprise technology utilization. Integrating metal cutting physics into CAD/CAM applications has important implications for improving the international competitiveness of SMEs.
Figure 1 illustrates a typical four stage sequence for machining a mechanical part using a traditional CAD/CAM system. Stage 1 builds a geometric model for the mechanical part to be machined. Stage 2 sets the machining processes to be used including cutter selection, cutting range dimensional data, coolant On/Off, fixture setup, machining type (rough milling, finish milling, etc.), machine tool configuration (e.g., a vertical milling machine center), and cutting parameters (depth of cut, feed rate, spindle speed). Stage 3 generates the tool path to create a cutter location file (CLFile). Stage 3 also includes tool path movement simulation, collision detection, and solid cutting verification. A numerical control (NC) program can be generated using a post-processer according to the machine tool configuration. Stage 4 then drives the assigned milling machine tool for actual cutting to produce the mechanical part according to the generated NC program which defines the machine tool's axes of motion and the 
actuation sequences of miscellaneous peripheral devices.

\begin{tabular}{|c|c|c|c|}
\hline $\begin{array}{c}<\text { Stage 1> } \\
\text { Build } \\
\text { geometric }\end{array}$ & $\begin{array}{l}\text { Product 3D } \\
\text { Model }\end{array}$ & $\begin{array}{l}\text { Machining } \\
\text { Model }\end{array}$ & $\begin{array}{l}\text { Workpiece } \\
\text { 3D Model }\end{array}$ \\
\hline $\begin{array}{l}<\text { Stage 2> } \\
\text { Set-up }\end{array}$ & $\begin{array}{c}\text { Tool } \\
\text { Setting }\end{array}$ & $\begin{array}{l}\text { Machining } \\
\text { Environment } \\
\text { Setting }\end{array}$ & $\begin{array}{l}\text { 3D Model } \\
\text { Settings }\end{array}$ \\
\hline $\begin{array}{l}\text { process and } \\
\text { parameters }\end{array}$ & $\begin{array}{l}\text { Machining } \\
\text { Fixture } \\
\text { Settings }\end{array}$ & $\begin{array}{l}\text { Process } \\
\text { Planning } \\
\text { Settings }\end{array}$ & $\begin{array}{l}\text { Machine } \\
\text { Tool } \\
\text { Settings }\end{array}$ \\
\hline \multirow{2}{*}{$\begin{array}{l}<\text { Stage 3> } \\
\text { Establish } \\
\text { Tool path }\end{array}$} & $\begin{array}{c}\text { Output Toolpath } \\
\text { File }\end{array}$ & $\begin{array}{l}\text { Toolpath } \\
\text { Simulation }\end{array}$ & $\begin{array}{c}\text { Toolpath } \\
\text { Generation }\end{array}$ \\
\hline & $\begin{array}{c}\text { Post-process NC } \\
\text { Program }\end{array}$ & $\begin{array}{l}\text { Controller and } \\
\text { Machine Tool } \\
\text { Configuration }\end{array}$ & $\begin{array}{c}\text { Gouge } \\
\text { Checking }\end{array}$ \\
\hline $\begin{array}{l}<\text { Stage 4> } \\
\text { Machining }\end{array}$ & $\begin{array}{l}\text { CNC Machine } \\
\text { Tool Machining } \\
\text { Implementation }\end{array}$ & & \\
\hline
\end{tabular}

Fig. 1. Typical sequence using a traditional CAD/CAM to machine a mechanical part.

Although feed per flute (tooth) makes a more appropriate cutting parameter, feed rate is generally used as a cutting parameter in the NC program, likely because feed rate is more easily defined and more intuitive for a human operator. The relation between the

Yung-Chou Kao is a Research Fellow and Head of the Division of Industry-University Cooperation at the Advanced Institute of Manufacturing with High-tech Innovations (AIM-HI) and a Joint Professor at the Department of Mechanical Engineering, National Chung University (CCU), Taiwan, since August 2014. He received his Ph.D. degree in 1998 in mechanical engineering from the University of South Australia (UniSA), Australia. He worked for the National Kaohsiung University of Applied Sciences (KUAS) as a professor from 2000 to 2014, lectured manufacturing engineering related subjects and established the Remote Virtual Rapid Manufacturing (RVRM) Laboratory in 2002. He has also set up the MAchinery Value ENgineering laboratory (MAVEN) in CCU. Dr. Kao had been invited to be the adviser of research organizations in Taiwan, including Metals Industry Research and Development Centre (MIRDC), and Precision Machinery Research and Development Center (PMC). He has published over one hundred and eighty papers including international journal and conference papers, held three patents and published three books. His teaching and research interests include Virtual Reality based machine tool simulator, smart manufacturing, remote digital manufacturing system, computer aided manufacturing, metal forming process simulation and die design optimization, multi-axes machining and emulations.

email: imeyckao@ccu.edu.tw

Da-Min Lin is conducting his PhD study at the Department of Mechanical Engineering, National Chung Cheng University, Chia-Yi, Taiwan. His research interests include digital manufacturing and networked intelligence. email: gn01675742@gmail.com

Jian-Zhang $\mathbf{W u}$ is conducting his Master degree study at the Department of Mechanical Engineering, National Chung Cheng University, Chia-Yi, Taiwan. His research interests include interactive machine tool simulation and chatter-free machining.

email: rsps950106@gmail.com

Trung-Kien Vi is conducting his PhD degree study at the Department of Mechanical Engineering, National Chung Cheng University, Chia-Yi, Taiwan. His research interests include Stability Lobe Diagram database establishment and calculation of cutting forces in supporting smart machining. email: vitrungkien@gmail.com feed rate and feed per flute is shown in Eq. (1). Feed per revolution is shown in Eq. (2), while the relationship between tool diameter, spindle speed, and cutting speed is shown in Eq. (3).

$$
\begin{aligned}
& \mathrm{F}=\mathrm{S} \times f_{z} \times Z \\
& f_{s}=f_{z} \times Z \\
& \mathrm{~V} \mathrm{c}=\pi \times D \times \mathrm{S}
\end{aligned}
$$

Where,

$$
\begin{aligned}
& \text { S: Spindle speed (RPM, rev/min) } \\
& \left.f_{Z}: \text { Feed per flute (tooth) ( } \mathrm{mm} / \text { tooth } / \mathrm{rev}\right) \\
& Z: \text { Number of flutes/teeth on the cutting tool (tooth) } \\
& \text { F: Feed rate }(\mathrm{mm} / \mathrm{min}) \\
& f_{s}: \text { Feed per revolution }(\mathrm{mm} / \mathrm{rev}) \\
& D: \text { Tool diameter }(\mathrm{mm}) \\
& V c: \text { Cutting speed }(\mathrm{mm} / \mathrm{min})
\end{aligned}
$$

Cutting speed $(\mathrm{Vc})$ represents the relative speed between the contact surface of the rotational milling cutter and the work-piece. Spindle speed can be calculated once " $\mathrm{Vc}$ " and tool diameter " $\mathrm{D}$ " are determined, as shown in Eq. (4). However, tool makers' technical manuals generally provide recommended spindle speed values for given work-piece material, tool materials, surface quality, tool diameter, number of tool flutes, and milling type (e.g., rough milling and/or finish milling). These manuals also generally provide recommended values for feed per flute and cut depth.

$$
\mathrm{S}=\mathrm{Vc} /(\pi \times D)
$$

Thus, the cutting parameter settings (e.g., Stage 2 of Fig. 1) are generally based on manufacturer recommendations and the practical experiences of the CAD/CAM engineers. On the other hand, if the NC program is written manually by an operator or a technician (as is the case in most of SMEs), cutting parameter assignments are highly dependent on the preferences and experience of the operator or technician. Therefore, CAD/CAM operations could significantly benefit from a smarter, more systematic, and more objective way of determining cutting parameters.

From the perspective of cutting mechanics theory, cutting processes in milling machining are characterized by intermittent contact between the cutter and work-piece, resulting in non-continuous cutting forces and uneven dynamic chip thickness [1]. Chatter during the machining process can cause unwanted work-piece surface roughness. As shown in Fig. 2, stability lobe diagrams (SLD) represent the relationship between axial cut depth and spindle speed. The stable zone (blue-colored area) is below the SLD curve. For example, 


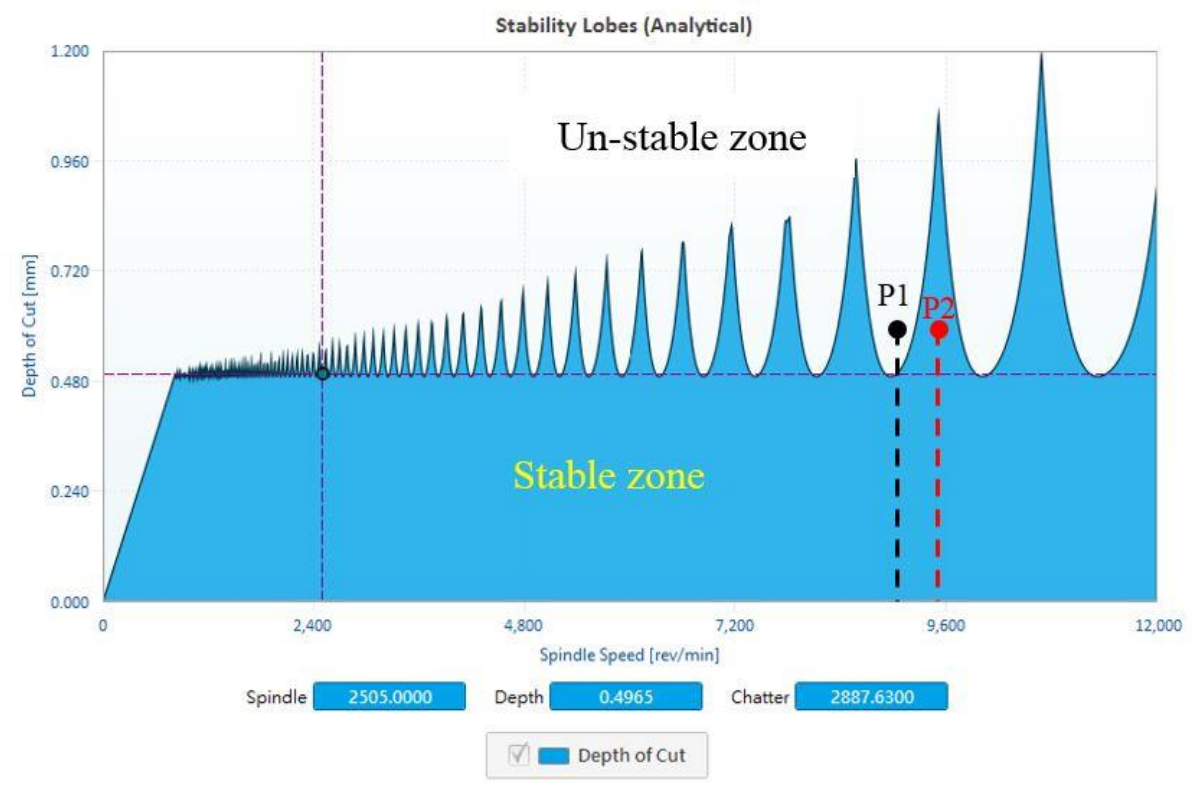

Fig. 2. Example of a stability lobe diagram (SLD).

P1 and P2 feature identical cut depths, but different spindle speeds, respectively producing stable and unstable cutting. This means the SLD is a good reference for a CAD/CAM engineer to assign an appropriate cut depth at a preferred spindle speed to generate the milling tool path. This SLD information could be integrated into CAD/CAM software to generate an optimal milling tool path.

Therefore, this paper focuses on the development of a CAD/CAM system that integrates SLDs to effectively determine the optimum cut depth and spindle speed for the generation of theoretically chatter-free pocket milling tool paths. The remainder of this paper is organized as follows. Section 2 describes the SLD and its applications, followed by a description of the cutting experiment to calculate the cutting force coefficients to support the generation of SLD. Section 3 presents a typical flowchart using a traditional CAD/CAM for comparison with the developed CAD/CAM with integrated SLD. A case study for pocket milling for the developed smarter cutting parameters selection integration system is then used for verification. Section 5 discusses results followed by conclusions.

\section{SLD and Related Works}

Stability lobe diagrams have emerged as a popular reference for determining the cut depth and spindle speed for the generation of stable and chatter free tool paths. The idea of SLD can be traced back to Tobias and
Fishwick [2], who noted that a machine tool's cutting stability is closely related to its spindle speed. Budak and Altintas drew an SLD based on an analytic formula for milling machining chatter stability. This formulation was also used to predict a chatter stability zone for milling machining, allowing for the maximization of the material removal rate (MRR) and machining efficiency, while preventing chatter. Furthermore, average cutting force was used alongside and cutting force coefficients as the basis to solve the axial limit cut depth and related spindle speed. This methodology was then extended for stability analysis of face tool milling, ball-end tool milling, and other special purpose tool milling. [3, 4] Chatter free cutting could also be achieved through monitoring audio signals [5], thus increasing milling efficiency and shortening machining time. Heidenhain developed an "Active Chatter Control (ACC)" [6] technique to inhibit chatter and enhance cutting efficiency for three- to five-axis milling machines, along with mill-turn machines.

Chatter can cause vibrations between the cutter and the work-piece, producing chatter marks on the work-piece surface which can both degrade surface quality and accelerate tool wear, generate noise and reduce machine tool lifespan. In the example shown in Figure 3 [7], the main cause of chatter is the last flute vibration mark having a 180 degree phase difference from the next flute.

Many studies have investigated cutting parameter optimization through chatter avoidance $[8,9,10,11,12]$ based on dynamic simulations and force models [13]. For example, Wu and Chang [9] used Unigraphics (UG) 
CAD/CAM to generate tool paths and conduct real cutting experiments, and analyzed resulting errors based on the measured results from a CMM (Coordinate measurement machine). The Taguchi method was adopted to reduce geometry errors. However, it seems that these methodologies have not been integrated into CAD/CAM systems.

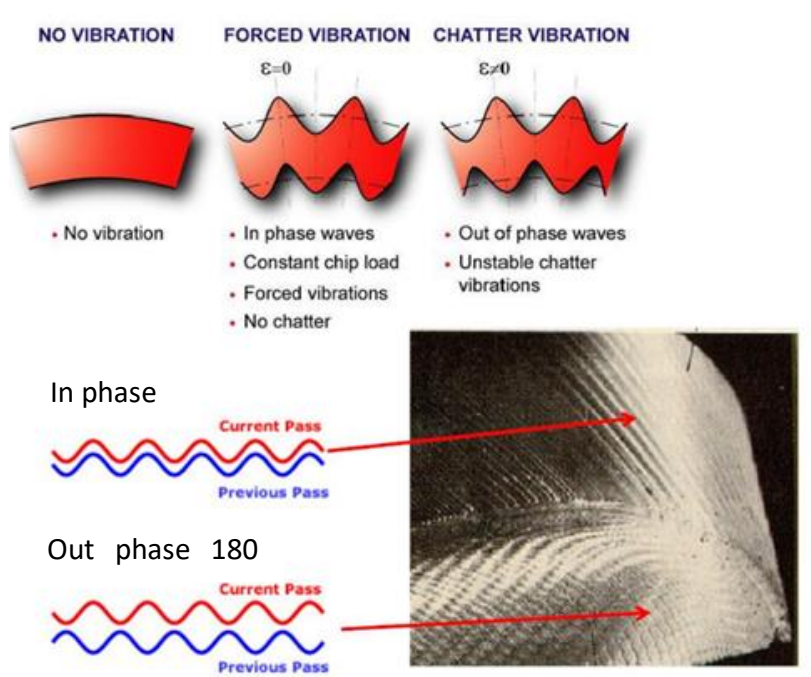

Fig. 3. Chatter marks [7].

Figure 4 shows a classic operation flow diagram using CAD/CAM [14], using UG CAD/CAM [15] as an example. However, the "Setup/Adjust the cutting parameters" step in Fig. 4 is commonly determined by a CAD/CAM user/engineer. Other CAD/CAM systems such as CATIA [16], Mastercam [17], and hyperMill [18] use similar operation flow diagrams. Therefore, a smarter CAD/CAM system for pocket milling is proposed and developed to provide users with more objective cutting parameter information.

\section{Realization of the Developed System}

Figure 5 shows the operation flow chart of the developed CAD/CAM system. Machine tool, material, and tool databases can be integrated into the proposed system in both "Data eXchange Format" (AutoCAD DXF) [19] and STL (STereoLithograph) file [20]. An STL file could be segmented to create the sectional profiles for the pocket contours including islands. Basic 2D geometry construction functions are also included to draw pocket contours, including "Line", "Arc", "Polyline", "Fillet", and "Chamfer". Tool path generation methods include "Pocket Milling" that can generate three-axis pocket milling tool paths with and without islands.

A material database contains the characteristic properties related to cutting a particular metal (e.g., aluminum alloy $\mathrm{Al}-6061-\mathrm{T6}$ and Al-7075-T6) such as

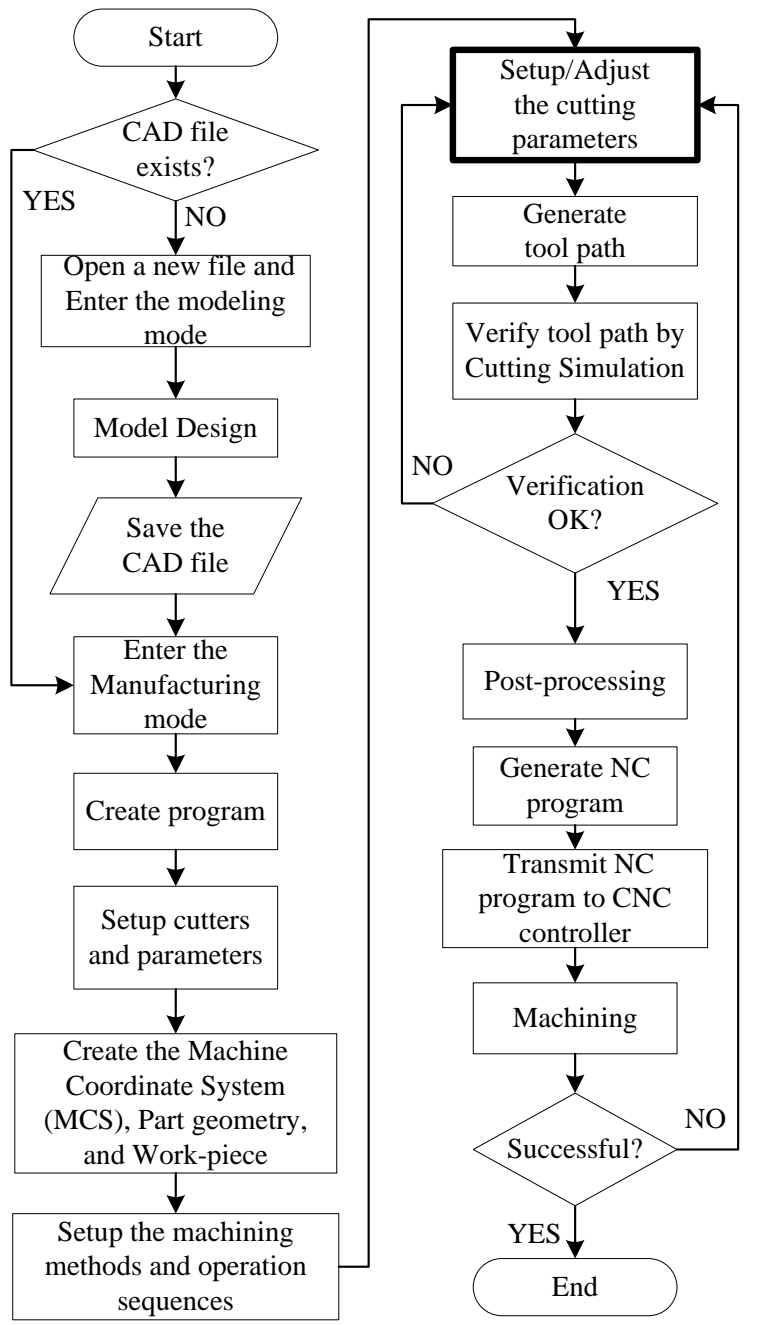

Fig. 4. UG NX CAD/CAM operation flow diagram.

cutting force coefficients. Work-piece geometry could also be defined by the user in both rectangular shapes (requiring width, depth, and height data) and cylindrical shapes (requiring diameter and length).

A tool database contains flat-end, ball-end, and fillet-end cutter geometry definitions, as shown in Figure 6. A flat-end tool could be defined in terms of tool flute diameter, flute length, helix angle, and total tool length; a fillet-end tool definition requires a corner radius. Cutting parameters include depth of cut, feed rate (i.e., approach, retract, cutting, and rapid movement feed rates), spindle speed, and radial width per cut. A machine tool database is comprised of machine configurations and SLD.

As shown in Fig. 2, an SLD depicts the relationship between depth of cut (limiting depth to avoid chatter) and spindle speed. The limiting depth of cut b_lim can be calculated from Eqs. (5) - (8). $R e\left[F R F_{\text {orient }}\right]$ is the real part of the oriented frequency response function $F R F_{\text {orient }}$, while $\operatorname{Im}\left[F R F_{\text {orient }}\right]$ is the imaginary part of the oriented frequency response function; $\emptyset_{s t}$ is the start angle of the cut while $\emptyset_{e x}$ is the exit angle. The 
force produced by the cutting operation is proportional to the frontal area of the chip through the cutting stiffness coefficient - $K_{s}$.

$$
\begin{aligned}
& b_{\text {lim }}=\frac{-1}{2 K_{S} R e\left[F R F_{\text {orient }}\right] N_{t}^{*}} \\
& N_{t}^{*}=\frac{\emptyset_{\text {ex }}-\emptyset_{\text {st }}}{\frac{360}{N_{t}}} \\
& \frac{f_{c}}{\mathrm{~S} N_{t}}=N+\frac{\varepsilon}{2 \pi} \\
& \varepsilon=2 \pi-2 \tan ^{-1}\left(\frac{\operatorname{Re}\left[F R F_{\text {orient }}\right]}{\text { Im[FRF } \left.F_{\text {orient }}\right]}\right)
\end{aligned}
$$

Where,

$b_{\text {lim }}$ : Limiting chip width (depth of cut) to avoid chatter

S: Spindle Speed

$N_{t}$ : Number of flutes of the tool (cutter)

$N_{t}^{*}$ : Average number of teeth in the cut

$f_{c}$ : Chatter frequency

$N$ : Integer number of waves of vibration imprinted on the work-piece surface in one revolution

$\varepsilon$ : Phase shift angle between current and previous tool vibrations:

$K_{s}$ : Cutting stiffness

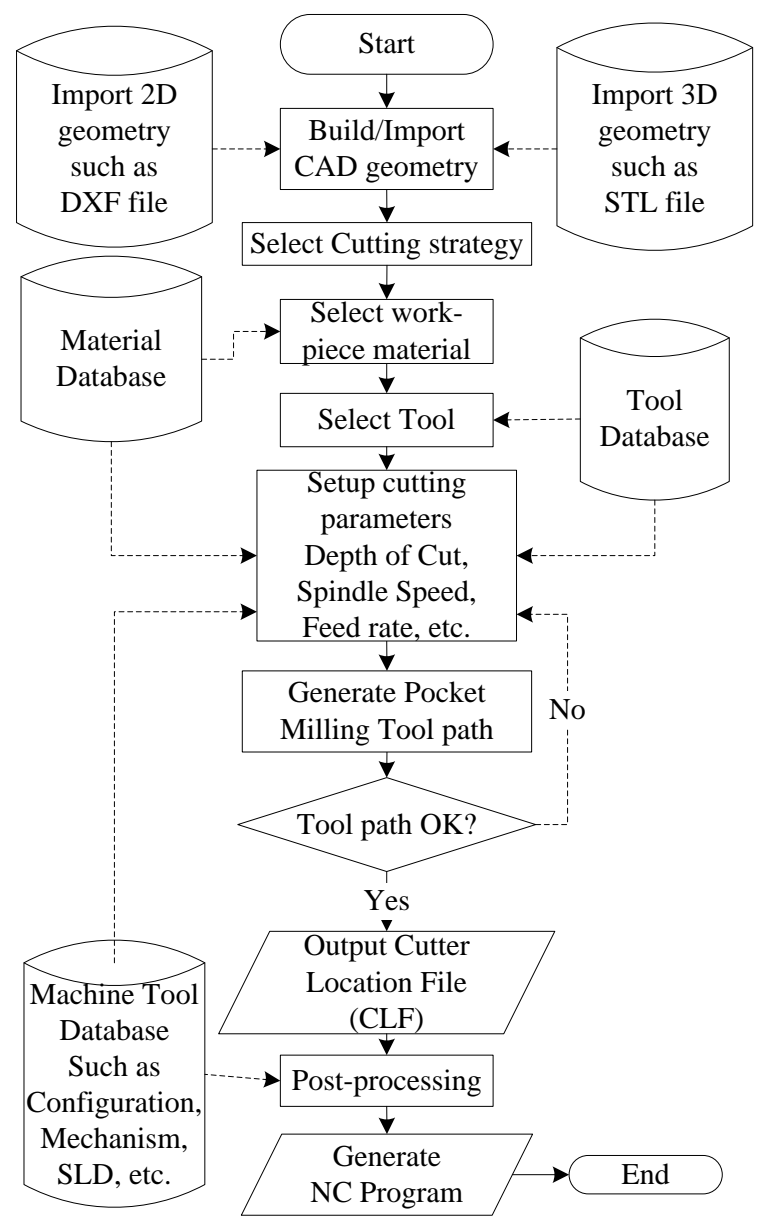

Fig. 5. Flow chart of the proposed system.

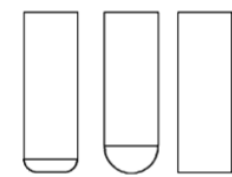

Fig. 6. Fillet-end, ball-end, and flat-end cutter geometry.

The cutting stiffness is related to the cutting force coefficients that can be obtained from a cutting test (see Fig. 7). However, this research used Cutpro ${ }^{\circledR}$ analysis software to obtain six cutting force coefficients according to the collected three-axis forces from the cutting test. Three-axis cutting forces $F_{x}, F_{y}, F_{z}$ could then be calculated via Eq. (9) from the cutting force coefficients. Cutpro ${ }^{\circledR}$ was also used to establish the SLD database.

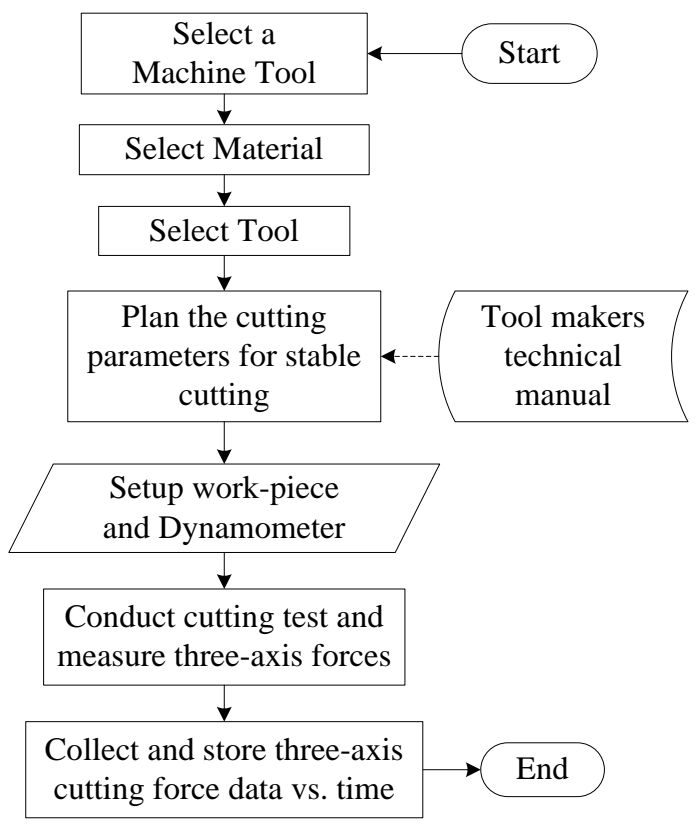

Fig. 7 Flow chart of cutting test.

Figure 8 shows the procedure for obtaining an SLD. Figure 9 shows a single-axis accelerometer (Kistler Type 8778A500M14sp) attached to the cutter, while Fig. 10 shows the hammer (Kistler 9722A2000) and data acquisition device (National Instruments High Speed USB Carrier - USB 9162). The adopted flat-end milling cutter has a diameter of $10 \mathrm{~mm}$, the referenced work-piece material is Aluminum AL-6061-T6, and the machine tool used is an NXV 560A milling machine tool manufactured by Yeong Chin Machinery Industries Co., Ltd. [21]. Figure 11 shows SLD for slot machining generated by Cutpro ${ }^{\circledR}$. [22] The SLD was outputted as an ASCII text file and stored in the SLD Database, as shown in Fig. 8. 


$$
\left\{\begin{array}{l}
F_{x}=-\frac{N_{t} a}{4} K_{r c} f_{z}-\frac{N_{t} a}{\pi} K_{r e} \\
F_{y}=+\frac{N_{t} a}{4} K_{t c} f_{z}+\frac{N_{t} a}{\pi} K_{t e} \\
F_{z}=+\frac{N_{t} a}{\pi} K_{a c} f_{z}+\frac{N_{t} a}{2} K_{a e}
\end{array}\right.
$$

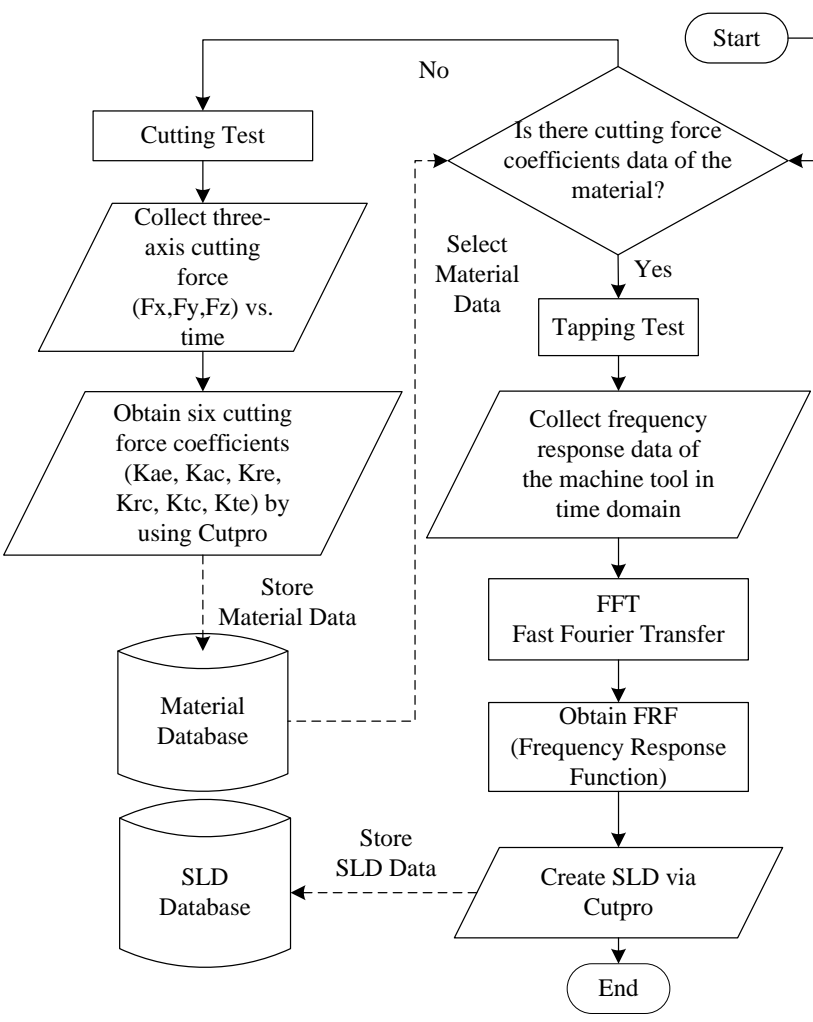

Fig. 8. Flow chart for obtaining SLD via Cutpro ${ }^{\circledR}$.

\section{Case Study of the Developed System}

To effectiveness of the proposed approach is verified on a pocket milling system. Figure 12 shows the graphical user interface (GUI) of the developed system where the offset profiles of a flame-shaped contour have been created and depicted in magenta.

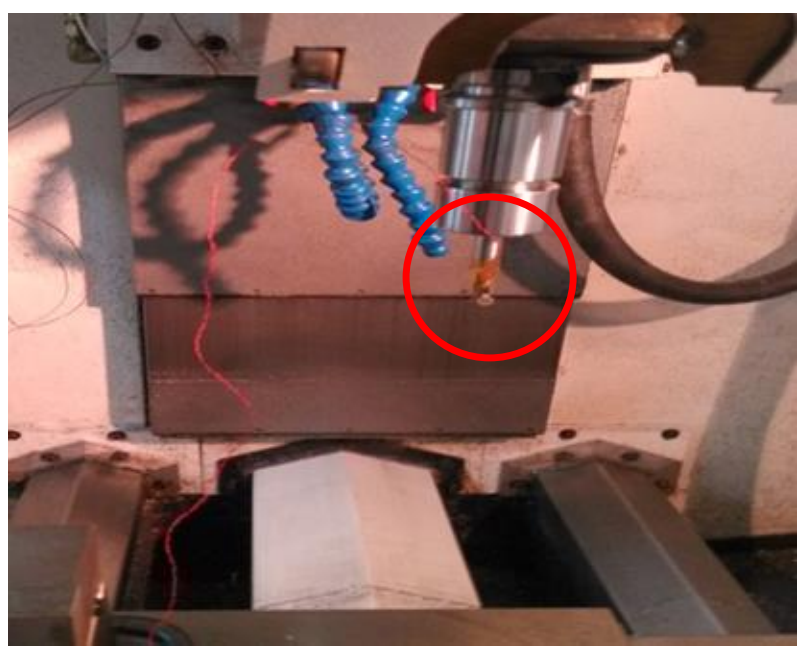

Fig. 9. Accelerometer attached to cutter.

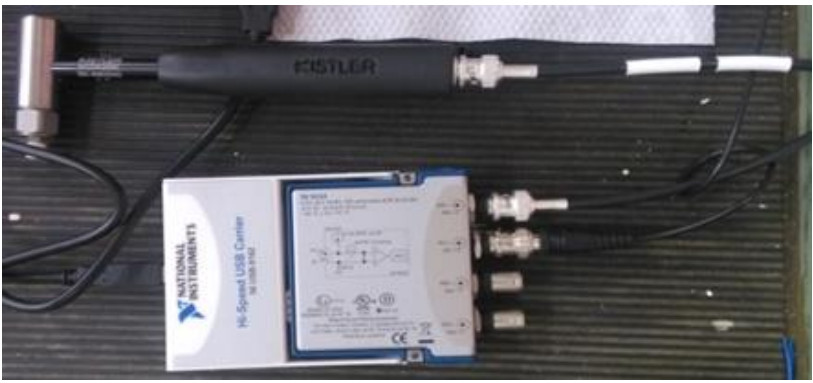

Fig. 10. Hammer and data acquisition device.

The stored SLD data is integrated with the developed pocket milling CAD/CAM and can be redisplayed, as shown in Fig. 13. The limiting depth of cut $b_{\text {lim }}$ is about $0.52 \mathrm{~mm}$. A two-headed pocket geometry, as shown in Fig. 14, was used as a case study for the creation of a five-layer pocket milling tool path.

The proposed cutting parameter selection function is implemented and integrated according to the limiting depth of cut - $b_{\text {lim }}$. That is to say, regardless of the spindle speed, no chatter occurs once the depth of cut is smaller than $b_{\text {lim }}$. For example, the chatter-free axial depth of cut could be 0.55 if the spindle speed is $4000 \mathrm{rpm}$, as shown by the green point at the middle right of Fig. 13.

Therefore, the depth of cut from the first to the fourth layer was set to the limiting layer $0.52 \mathrm{~mm}$, while that the fifth layer was $0.4 \mathrm{~mm}$. As shown in Fig. 15, the generated pocket tool path has five layers. The tool path can be simulated in a wire frame, as shown in Fig. 16 , with a solid cutting simulation shown in Fig. 17 . The program zero origin could be assigned, as shown in Fig. 18 , and Fig. 19 shows the post-processed NC program.

\section{Conclusion}

This research successfully integrates stability lobe diagram (SLD) information into a pocket milling CAD/CAM system. Depth of cut assignment for pocket milling tool path generation can reference an SLD created via Cutpro ${ }^{\circledR}$ based on a tapping test of the spindle speed. This creates a means of assigning objective settings for the depth of cut and spindle speed which heretofore rely subjective interpretation of tool maker's technical manuals or machine tool operator experience. A case study implementation successfully demonstrates the effectiveness of the proposed integration method, but further studies using additional SLDs in the SLD database, along with a wider range of materials, cutting tools, and cutting strategies should be conducted to extend the application of the proposed methodology. Integration of the SLD with existing CAD/CAM systems is also 
achievable through third-party software development kits (SDK) and/or application programming interfaces
(API). Future work will also explore and integrate cutting force calculations for the estimation of tool deflection.

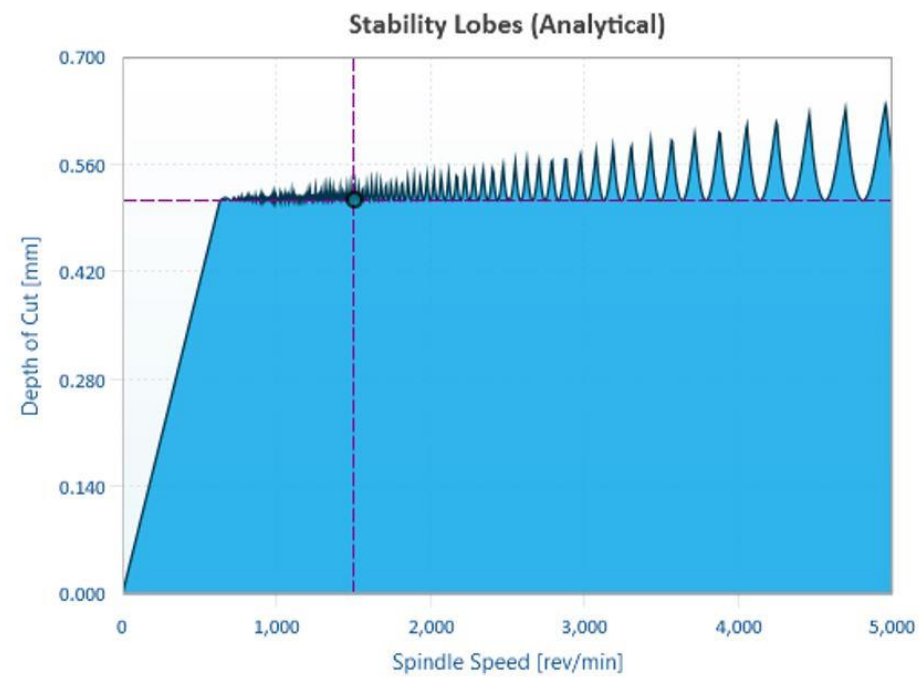

Fig. 11. SLD for slot machining displayed by Cutpro ${ }^{\circledR}$.

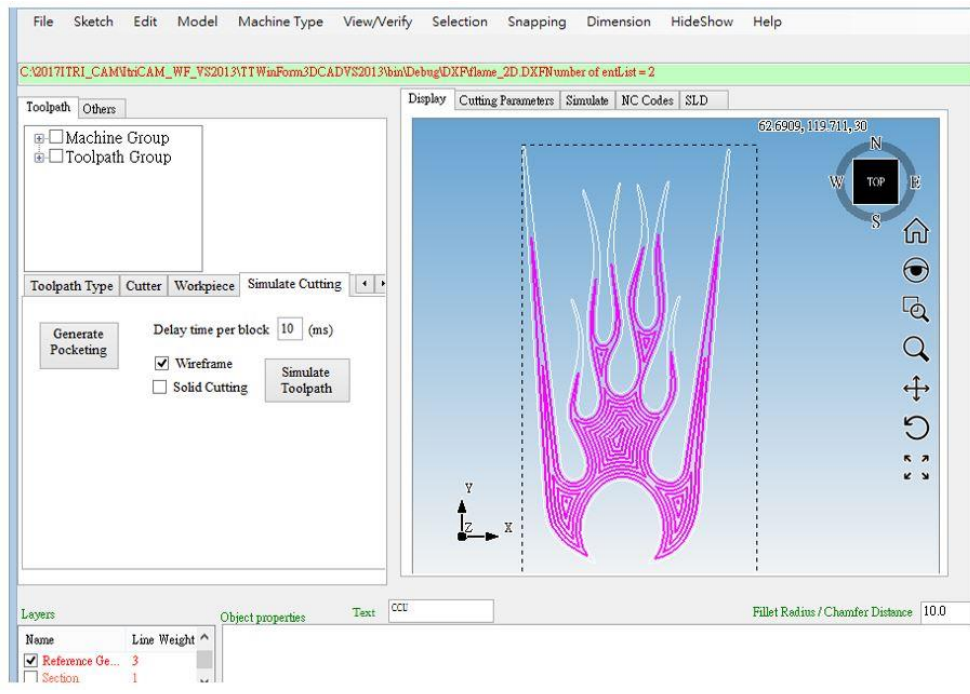

Fig. 12. System GUI.

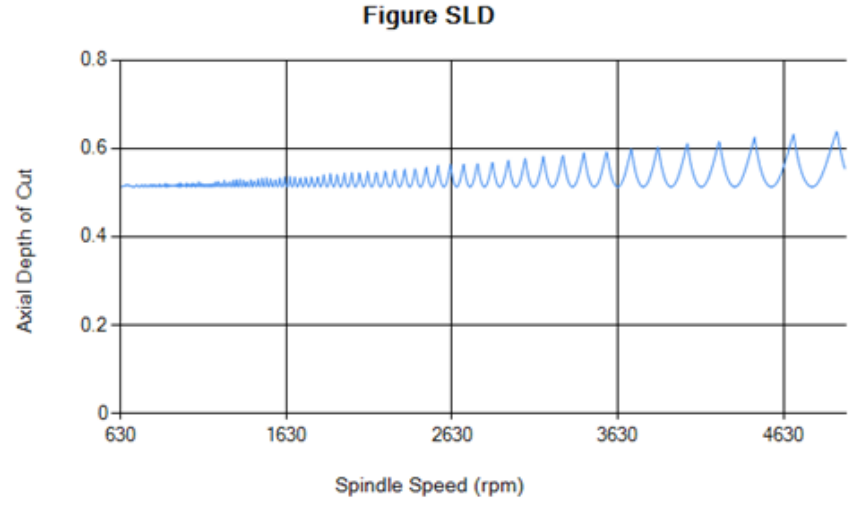

Fig. 13. SLD for slot machining displayed by the developed pocket milling CAD/CAM.

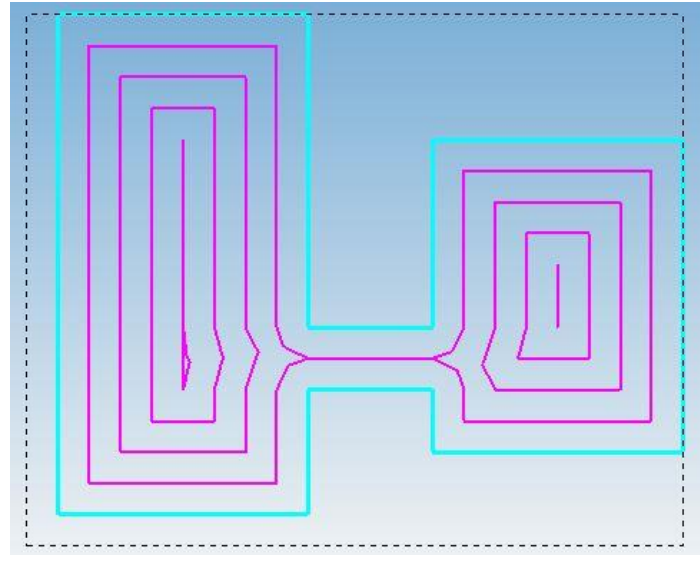

Fig. 14. Two-headed contour used in the case study. 


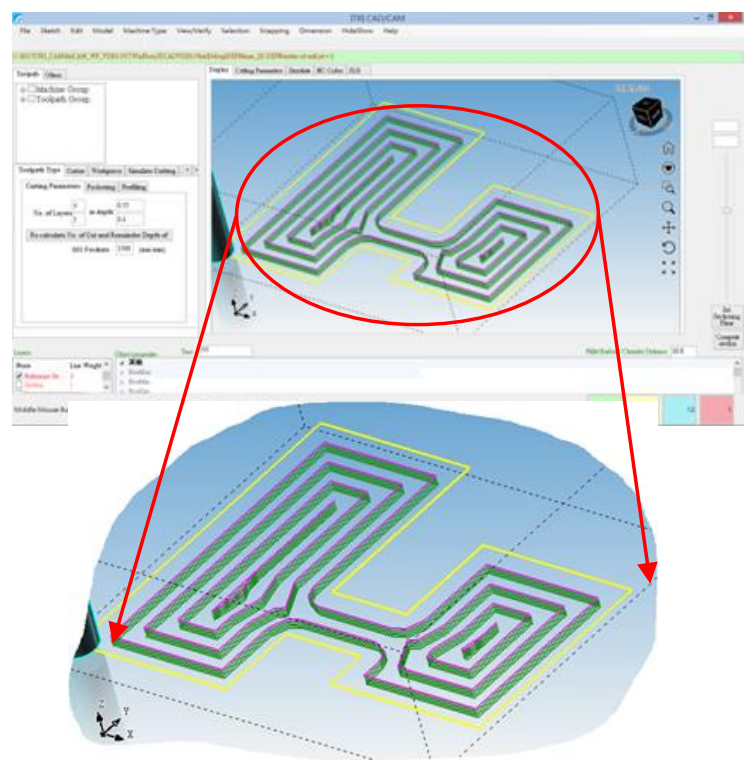

Fig. 15. System GUI.

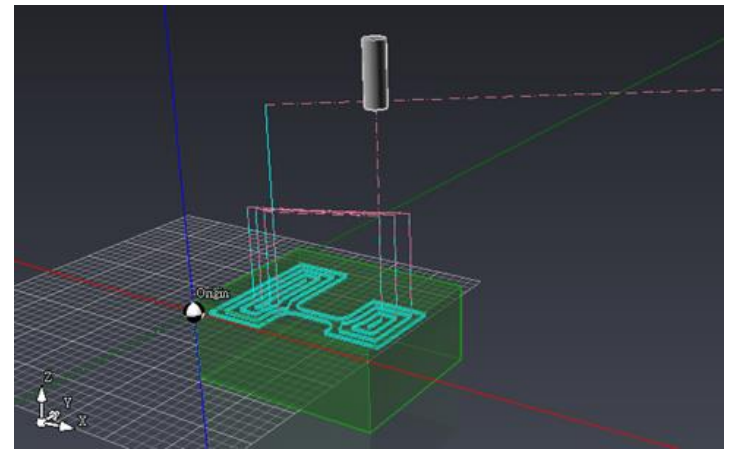

Fig. 16. Tool path simulation in wire frame mode.

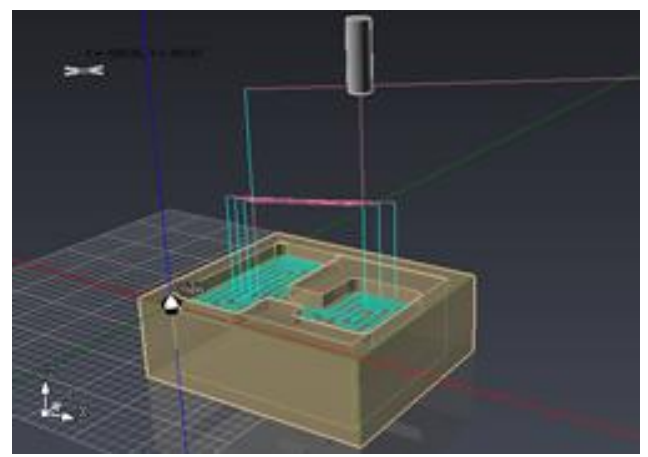

Fig. 17. Tool path simulation in solid cutting mode.

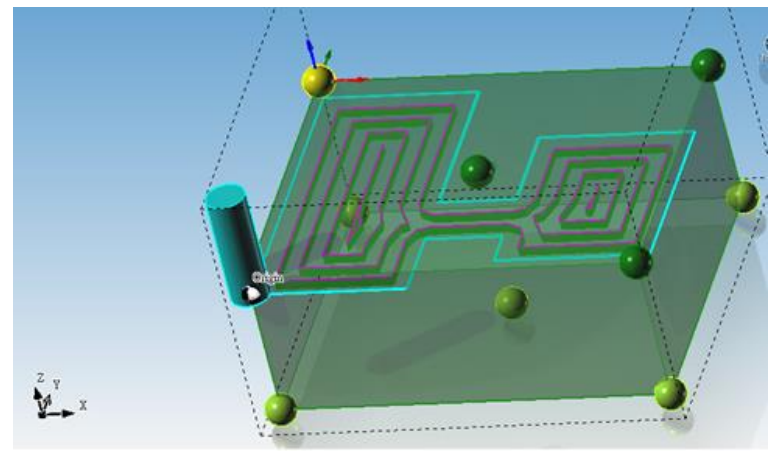

Fig. 18. Program zero origin is selected.
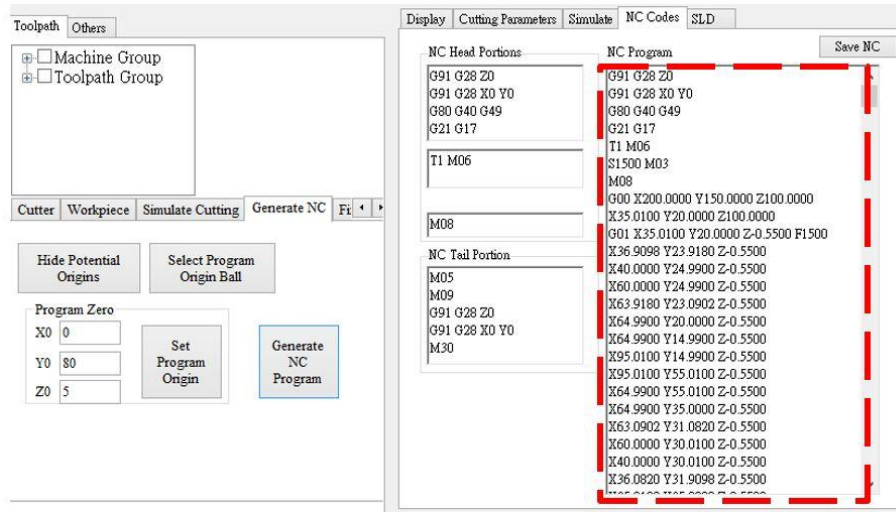

Fig. 19. Post-processed NC Program.

\section{Acknowledgments}

This study was supported by a grant from Taiwan's Ministry of Science and Technology (MOST106-2221-E-194-032).

\section{References}

[1] T. Schmitz and K. Smith., "Machining-Dynamics Frequency Response to Improved Productivity," ISBN 978-0-387-09644-5, page 117, 2009. doi: 10.1007/978--0-387-09645-2

[2] S. Tobias and W. Fishwick, "Theory of Regenerative Machine Tool Chatter," Engineering, vol.205, 1958.

[3] Y. Altintas, E. Shamoto, P. Lee, and E. Budak, "Analytical Prediction of Stability Lobes in Ball End Milling," ASME Journal of Manufacturing Science and Engineering, vol. 121, no. 4, pp.586-592, Nov. 1999.

doi: $10.1115 / 1.2833064$

[4] Y. Altintas, "Manufacturing Automation: Metal cutting mechanics, machine tool vibrations, and CNC design," in Cambridge University Press, 2012

[5] OKUMA, "Machining Navi," Online accessed, Dec. 27, 2016.

Available:

http://www.OKUMA.co.jp/onlyone/process/index. html.

[6] Heidenhain, "Active Chatter Control, ACC," Online accessed, Dec. 27, 2016.

Available:

http://www.heidenhain.hu/hu HU/hirek/news-sin gle-view/news/heidenhain-at-the-emo-2015greate r-efficiency-through-accuracy/

[7] D.-R. Peng, "Machine Tool Structure Design and Analysis," Industrial Technology Research Institute, Hsinchu, Taiwan, Tech. Rep., Sep. 2016.

[8] Z.-Q. Li, S. Li, and M. Zhou, "Study on Dynamic 
Simulation and Cutting Parameters Optimization of Complex Cutting Conditions Milling Process," in proceeding of International Conference on Intelligent Computation Technology and Automation, Changsha, China, May 11-12, 2010, pp. 501-504. doi: $10.1109 /$ ICICTA.2010.240

[9] G. Wu and M.-H. Zhang, "Optimization of Cutting Parameters in Machining Surface to Reduce Errors," in proceeding of IEEE $2^{\text {nd }}$ International Conference on Computing, Control and Industrial Engineering, Wuhan, China, Aug. 20-21, 2011, pp. 200-203. doi: 10.1109/CCIENG.2011.6007992

[10] R. Horváth and E. Tóth-Laufer, "Fuzzy model-based cutting parameter combination optimization," in proceeding of $18^{\text {th }}$ International Conference on Intelligent Engineering Systems, Tihany, Hungary, July, 3-5, 2014, pp. 151-155. doi: $10.1109 /$ INES.2014.6909359

[11] W. Zhao, Y.-G. Li, C.-Q. Liu, and W.-M. Shen, "A Cutting Parameter Optimization Method Based on Dynamic Machining Features for Complex Structural Parts," in proceeding of IEEE $20^{\text {th }}$ International Conference on Computer Supported Cooperative Work in Design, Nanchang, China, May 4-6, 2016, pp. 85-90. doi: $10.1109 / C S C W D .2016 .7565968$

[12] I. Bediaga, I. Egaña, J. Munoa, M. Zatarain, and L.N. López de Lacalle, "Chatter avoidance method for milling process based on sinusoidal spindle speed variation method: simulation and experimental results," in proceeding of 10th CIRP International Workshop on Modeling of Machining Operations, Reggio Calabria, Italy, Aug 2007.

[13] K. Karunakaran, R. Shringi, D. Ramamurthi, and C. Hariharan, "Octree-based NC simulation system for optimization of feed rate in milling using instantaneous force model," International Journal of Advanced Manufacturing Technology, vol. 46, no. 46, pp. 465-490, Jan. 2010.

doi: $10.1007 / \mathrm{s} 00170-009-2107-7$

[14] Y.-C. Kao, J.-Y. Lee, and Y.-S. Zheng, "Pocketing Toolpath Generation and Simulation with Cutting Force Estimation," in Proceedings of the 34th Conference of China Mechanical Engineering Symposium, Taichung City, Taiwan, Dec. 1-2, 2017.

[15] UG NX CAM, Online Accessed, Sept. 28, 2017. Available: https://www.plm.automation.siemens.com/en/pro ducts/nx/for-manufacturing/cam/index.shtml

[16] CATIA CAD/CAM, Online Accessed, Sept. 28, 2017. Available: https://www.3ds.com/products-services/catia/

[17] Mastercam, Online Accessed, Sept. 28, 2017. Available: http://www.mastercam.com/en-us/

[18] hyperMill CAD/CAM, Online Accessed, Sept. 28, 2017.

Available: http://www.openmind-tech.com/en/cam/new-in-h ypermill/version-2017-1.html

[19] AutoCAD DXF, Online Accessed, Sept. 24, 2017., Available: https://en.wikipedia.org/wiki/AutoCAD DXF

[20] STL (file format), Online Accessed, Sept. 24, 2017. Available: https://en.wikipedia.org/wiki/STL (file format)

[21] Yeong Chin Machinery Industries Co., Ltd, Online Available: http://www.ycmcnc.com/index en.php

[22] CUTPRO PDF GUIDE, Online Accessed, Jan. 20, 2017.

Available: http://www.malinc.com/wp-content/uploads/2014 /05/CutPro Guide.pdf 